so far distant as to permit a piece of drawing paper to slide easily between them. They are of a rectangular form, fastened on three sides in any manner which shall leave the surfaces parallel. The fourth side being open, the space within is partly filled with pure quicksilver. By means of a slip of drawing paper, the outer edge of the quicksilver is made straight and rectangular with the sides. Its position is then marked. This may be done by noting on the paper used, its distance from the outer and open edge of the glasses.

The plot of any irregular plot made from field notes or otherwise, is then moved in till the quicksilver extends to that point of the plot which is nearest the outer and open elge. The outer edge being now parallel to the former edge by the manner in which the paper containing the plot is cut, its distance from its former edge is measured or marked on the same paper, and the area of the irregular field is thus found to be the difference of the areas of two given rectangles.

The committee see no reason why such an instrument should not, when constructed with proper care, give results as accurate as those obtained by the common method of plotting, and dividing into right angled triangles by the dividers and plane scale. The area of the rectangle of any irregular plot, when once completed, may thus be formed in five minutes, and all danger of mistake from, errors in the entries or in summing up the partial areas is completely obviated.

The committee consider this very useful and ingenious invention worthy of the Scott's Legacy Premium, and respectfully recommend it for the same.

By order of the Committee.

March 14, 1839.

William Hamleton, Actuary.

\title{
Report on Mr. L. E. Denison's Corn Sheller.
}

The Committee on Science and the Arts constituted by the Franklin Institute of the State of Pennsylvania, for the promotion of the Mechanie Arts, in whom was referred for examination a Corn Sheller, invented by Mr. L. E. Denison, of Sayville, Middle. sez county, Connecticut, Reront:

That the peculiarity of this machine consists in the mode of feeding and retaining the ears of corn in contact with the shelling cylinder. The feeding is effected by surrounding the cylinder with a case termed by the inventor, a revolving concentric cylindrical rest.

This case is formed of a number of bars or staves, the ends of which are mortised into the peripheries of two circular heads. The staves are placed at sufficient distance apart to admit an ear of corn between them, and the diameter of the case is such that the stave just clears the pins or teeth of the shelling cylinder within it. The cylinder and its case both revolve on a common centre and in the same direction, the cylinder making about ten revolutions to one of the case. Beneath the case is a series of metal bands surrounding about one half its circumference, and pressed against the stave by spiral springs; this is termed the segment concave; it is divided into sections which are independent of each other, so that 
ears of different size may follow in immediate succession without difficulty.

The ears of corn are placed parallel to the axis of the shelling cylinder in a hopper fixed on one side of the machine. As the cylindrical rest revolves, an ear falls into each space between the staves, and is kept in contact with the shelling cylinder, by the pressure of the segment concave; the grain shelled falls beneath the machine, and the cob is delivered at the side opposite to the hopper, after having been in contact with the cylinder during four or five revolutions.

The arrangement of this machine is different from any that has before fallen under the notice of the committee, and although it may seem somewhat complicated at first view, a farther inspection will show that it is as simple in construction as many other analogous machines. Its operation in the presence of some members of the Institute was highly satisfactory; the cobs were thrown out whole and divested of every grain, and the power requisite to keep it in action was less than in many other machines heretofore in use. As this invention appears to be both new and useful, the committee believe it to be a proper object for an award of the Scott legacy premium, and recommend such award under the usual condition.

By order of the Committee.

October 10, 1839.

William Hamilton, Actuary.

\section{Commitree on Premiums and Exmibitions.}

The report of the judges on Bookbinders' work and Tools-exhibited at the late exhibition of American Manufactures, held by the Franklin Institute, having been pasted by the judges to the invoice, was, by mistake, filed among the invoices, and consequently overlooked. The attention of the committee having been called to the omisssion by one of the judges, they with pleasure correct the oversight by publishing the following report.

Com. on Prem. and Exhib.

\section{Report of the Judges on Bookbinders' Work and Tools.}

The Committee of Judges on Bookbinders' Work and 'Tools Report that they have examined the articles exhibited as per list No, 32, and offer the following as the result:

No. 412. A case containing 31 Bibles, and 2 vols. of Switzerland-in consequence of the vols. not being accessible to the Committee for examination, they cannot speak as to the particular merits of the workmanship, but state that they exhibit a very considerable degree of taste and judg. ment in the design and execution of the finishing, and they doubt not that the workman, by attention and perseverance, will be enabled to produce work of a highly creditable character.

No. 523. A case containing 9 books, among which are a vol. of blank paper bound for the purpose of procuring signatures to the Indian Biography; and a copy of the Waldenses-both of which are done in a most splen. did super extra fancy style, displaying a degree of taste in design, and judgment in execution, very rarely combined-also a copy of Byron, bound in Morocco super extra with a flexible back, deservedly of a most praiseworthy character, alike in regard to solidily, strength and beauty. There is also in same case vols. of "the Gift," Girls" and Boys' Scrap Books, and a 